Preprint version. Published version available: Surface and Coatings Technology (2018), vol. 349, pp. 719-724. https://doi.org/10.1016/j.surfcoat.2018.06.043

\title{
Evaluation of macro- and microscopic residual stresses in laser shock-peened titanium alloy by FIB-DIC ring-core milling with different core diameters
}

\author{
Joris Everaerts ${ }^{1}$, Xu Song ${ }^{2}$, Balasubramanian Nagarajan ${ }^{2}$, Alexander M. Korsunsky ${ }^{1}$ \\ ${ }^{1}$ Department of Engineering Science, University of Oxford, Oxford OX1 3PJ, UK \\ ${ }^{2}$ SIMTech, A*Star Singapore Institute of Manufacturing Technology, Singapore
}

\section{Highlights}

- FIB-DIC residual stress analysis in LSP titanium shows microstructural size effect

- $10 \mu \mathrm{m}$ ring-core results agree with mean macro-stress from synchrotron XRD data

- $5 \mu \mathrm{m}$ ring-core results show scatter caused by Type II microscopic residual stresses

- Type II contributions cause local tension in a macroscopically compressed zone

\begin{abstract}
The residual stresses in a laser shock-peened (LSP) plate of titanium alloy were analysed by means of the ring-core Focused Ion Beam - Digital Image Correlation (FIB-DIC) technique using pillar diameters of $10 \mu \mathrm{m}$ and $5 \mu \mathrm{m}$. A cross-section of the Ti-6Al-4V laser shock peened plate was electrochemically polished to avoid induced residual stress modification due to grinding. FIB-DIC measurements with pillar diameters of $10 \mu \mathrm{m}$ show that a near-surface compressive residual stress of approximately $350 \mathrm{MPa}$ is present in the direction parallel to the peened surface. This changes to a tensile residual stress of approximately $100 \mathrm{MPa}$ at the depth of $2 \mathrm{~mm}$, and then changes back to a small compressive residual stress on the opposite face. These results are in good agreement with the previously obtained set of measurements using
\end{abstract}


high-energy synchrotron X-ray diffraction. However, FIB-DIC measurements with pillar diameters of $5 \mu \mathrm{m}$ show strong deviations from this general macroscopic trend that corresponds to the macroscopic average (Type I) residual stresses. The reason for the apparent discrepancy lies in the smaller gauge volume used in the second set of measurements, which causes the evaluated residual stress values to be dominated by the microscopic (Type II+III) residual stress components. These Type II+III residual stresses are the result of the local microstructure and intra- and intergranular interactions. The results demonstrate that the Type II+III stresses have significant magnitude sufficient to produce local tensile stress in the region that is subjected to macroscopic compression due to LSP treatment, and vice versa. The implications of this finding are discussed.

Keywords: Titanium; Laser shock peening; Residual stress; FIB-DIC; Ti-6Al-4V 


\section{Introduction}

Laser shock peening (LSP) is a surface processing technology that provides the means to create compressive residual stresses up to relatively large depths into metal surfaces. This technique is consequently used to improve the fatigue life and resistance to fretting fatigue of metallic materials by enhancing the resistance to near-surface crack initiation and propagation. [1-3] Laser shock peening can also increase the resistance to high temperature oxidation by causing a reduction in oxygen diffusion coefficient. [4] The LSP process overcomes certain limitations of traditional shot peening, such as a limited depth of compressive residual stress and roughening and contamination of the surface. Laser shock peening consists of first applying a laser absorbent coating and optionally an additional laser transparent coating to the surface, and then exposing it to a high power Q-switched laser. The laser, which generally provides energy densities in the $\mathrm{GW} / \mathrm{cm}^{2}$ range, generates a local high-pressure plasma between the absorbent coating and the metal surface, which causes a shock wave into the material. The optional transparent coating leads to an increase in shock wave intensity by essentially trapping the generated plasma and preventing it from expanding away from the surface. [5] The shock waves, which travel in the direction normal to the sample surface, cause tensile plastic deformation of the material near the surface in the plane parallel to the surface. As a result, compressive residual stress normal to the impact direction is induced in this near-surface region, generally up to a depth of a few millimetres, and a balancing tensile residual stress is created in the deeper layers. [6]

Measurements of the residual stress profile caused by laser shock peening most often rely on $\mathrm{X}$-ray diffraction (XRD) techniques, using either laboratory X-ray sources and diffractometers [7-10] or high-energy X-rays at synchrotron facilities. [3,11] Alternatively incremental hole drilling has been reported as residual stress analysis method for LSP. [5,12] However, both of these techniques only provide information on the macroscopic residual stress because the 
analysed volume is relatively large i.e. comprises a large number of grains. In other words, the measured residual stress is an average over all of the grains within the gauge volume. It is well known that the total residual stress at a specific point in the material is in fact the sum of Type I, II and III residual stress. According to this classification, Type I residual stresses are macroscopic, whereas Type II+III residual stresses are the result of the local microstructure and inter- and intragranular interactions. [13] These microscopic contributions to residual stress play an important role in for example fatigue crack initiation and short crack growth, which is governed by phenomena at the grain level. [14] Moreover, the intergranular interactions, i.e. between neighbouring grains, are particularly strong in hexagonal close-packed polycrystals such as titanium alloys, due to their high lattice anisotropy. $[15,16]$

The possibility to measure residual stress in a well-defined micro-scale gauge volume has been achieved by the development of the Focused Ion Beam - Digital Image Correlation (FIB-DIC) ring-core milling technique. [17] This semi-destructive technique is based on the principle of strain relief after material removal. A FIB is used for incremental milling of a circular trench, which leads to the formation of a central core, or micropillar. By ensuring that the top surface of this micropillar carries a stable contrast pattern, it is possible to measure the strain relief by means of DIC analysis of scanning electron microscopy (SEM) images, while the material is experiencing gradual strain relief due to progressive milling. Careful analysis by simulation and modelling has confirmed that the micropillar is fully relieved of residual stresses when the milling depth becomes approximately equal to its diameter. The relief strain can be used to calculate the local residual stress that was present prior to milling. [18] In contrast to the aforementioned techniques for measuring residual stress, the gauge volume that is analysed by FIB-DIC ring-core milling is small enough to be sensitive to Type II and III residual stresses. 
The purpose of this paper is to present the results of residual stress measurements by FIB-DIC ring-core milling on a laser shock-peened titanium alloy plate. These results are compared to a previously obtained set of measurements on the same sample using high-energy synchrotron X-ray diffraction [11] and an eigenstrain model. [20] As will be shown, FIB-DIC ring-core milling can be used to obtain both macroscopic 'average' (Type I) and local (sum of Type I+II+III) residual stress values, by simply tuning the core diameter with respect to the grain size of the material.

\section{Material and methods}

The material used in this study is a Ti-6Al-4V alloy plate with a thickness of $8.5 \mathrm{~mm}$, which was laser shock peened by means of a Nd:YAG laser with an approximate energy density of 7 $\mathrm{GW} / \mathrm{cm}^{2}$ and impulse duration of $20 \mathrm{~ns}$. The spot size was circa $2 \times 3 \mathrm{~mm}^{2}$, with a coverage of 200\%. After LSP the plate was cut using a wheel cutter. The thus obtained cross-section was mounted in epoxy resin and ground up to a grit of 2400. This was followed by electrochemical polishing for 10 minutes with a current density of $2 \mathrm{kA} / \mathrm{m}^{2}$ in an electrolyte containing $700 \mathrm{ml} / \mathrm{l}$ ethanol, $300 \mathrm{ml} / \mathrm{l}$ isopropanol, $60 \mathrm{~g} / \mathrm{l}$ aluminium chloride and $250 \mathrm{~g} / \mathrm{l}$ zinc chloride, which removed a surface layer of approximately $0.1 \mathrm{~mm}$.

All SEM imaging and FIB milling was performed using a Tescan LYRA3 FIB-SEM microscope. An Oxford Instruments NordlysNano detector was used for electron backscatter diffraction (EBSD) measurements. Ring-core FIB-DIC measurements were carried out with a pillar diameter of 5 or $10 \mu \mathrm{m}$ and trench width of $1 \mu \mathrm{m}$. Prior to these measurements, the sample was coated with a thin Pt layer. A pattern suitable for DIC could then be created by performing two FIB scanning passes on the investigated area. The ion beam energy and current were 30 $\mathrm{keV}$ and $0.27 \mathrm{nA}$, respectively. FIB milling was performed in 40 incremental steps of $125 \mathrm{~nm}$ or $250 \mathrm{~nm}$ for the measurements with 5 or $10 \mu \mathrm{m}$ pillar diameter, respectively. In other words, 
the total milling depth was chosen to be equal to the pillar diameter, which ensures that the micropillar is fully relieved of residual stresses as confirmed by finite element modelling. [18] The obtained relief strain curves as a function of milling depth were fitted to the master curve function as described by Korsunsky et al. [18] to obtain the relief strain components in the $x$ and $y$ directions. The $x$ and $y$ directions are defined as being parallel and perpendicular to the peened surface, respectively, as is illustrated in Figure 1.

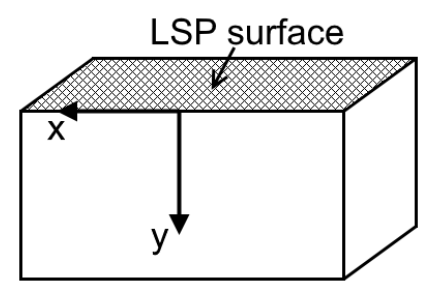

Figure 1. Sample geometry and definition of coordinate system

The stress state is assumed to be non-equi-biaxial, which means that the residual stress in the $x$ direction, $\sigma_{x}$, and in the $y$ direction, $\sigma_{y}$, can be calculated as: [17]

$$
\begin{gathered}
\sigma_{x}=-\frac{E}{\left(1-v^{2}\right)}\left[\Delta \varepsilon_{x}+v \Delta \varepsilon_{y}\right] \\
\sigma_{y}=-\frac{E}{\left(1-v^{2}\right)^{[}}\left[v \Delta \varepsilon_{x}+\Delta \varepsilon_{y}\right]
\end{gathered}
$$

In these equations, $E$ is Young's modulus, $v$ is Poisson's ratio, and $\Delta \varepsilon_{x}$ and $\Delta \varepsilon_{y}$ are the relief strains in the $x$ and $y$ direction, respectively. The values used for $E$ and $v$ were $110 \mathrm{GPa}$ and 0.3 , respectively. [16] The error calculations for ring-core FIB-DIC measurements have been described in detail by Lunt \& Korsunsky [21] and in this case take into account the error as a result of DIC analysis, the error caused by fitting the data to the master relief curve, and the error caused by assuming an average Young's modulus. All of the error bars for FIB-DIC ringcore data in this study represent a $95 \%$ confidence interval. 
A set of measurements was collected previously using high-energy synchrotron X-ray diffraction. [11] The results contain residual elastic strain data for multiple reflections that correspond to ensemble averages from groups of grains that have certain orientation with respect to the laboratory system (scattering vectors), as well as with respect to the crystal lattice (Miller indices). It has been shown previously that adequate reconstruction of macroscopic average residual elastic strain is obtained by weighted averaging of the strains from multiple reflections. [22] To allow making a comparison between the synchrotron data and the current set of results, residual stress $\sigma_{\text {res }}$ was calculated from the mean residual elastic strain $\varepsilon_{\text {res }}$ by using Hooke's law in the form

$$
\sigma_{r e s}=E \varepsilon_{\text {res }}
$$

This simplifying assumption is appropriate due to the fact that the principal kinematic deformation mode corresponds closely to bending. [23] Under classical Kirchhof bending theory, the transverse stresses within a bent bar are zero, and the longitudinal stress-strain relationship is described by the equation above.

\section{Results}

Figure 2 shows a secondary electron image of the surface after electrochemical polishing. The typical microstructure consists of equiaxed primary $\alpha$ phase (hexagonal close-packed) grains and two-phase regions containing $\beta$ phase (body centred cubic) and secondary $\alpha$ phase. 


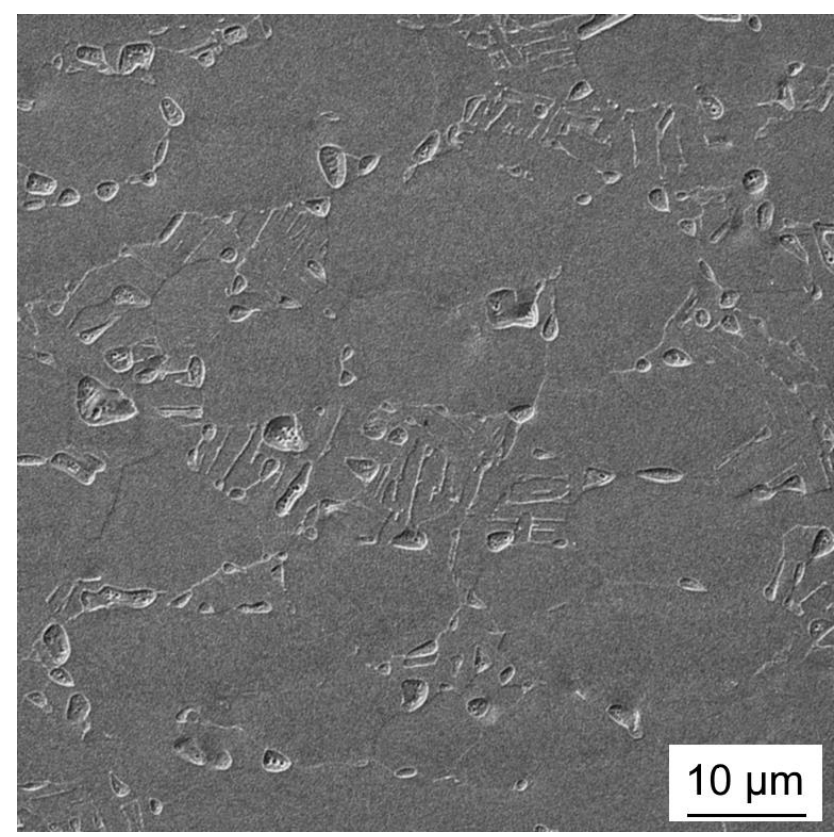

Figure 2. Secondary electron image of electrochemically polished cross-section of the Ti-6Al-4V plate

From the SEM image in Figure 2, it can be estimated that the primary $\alpha$ grain size is approximately $5 \mu \mathrm{m}$. [11] However, a more accurate calculation has been obtained by EBSD mapping, as is shown in Figure 3. Based on this inverse pole figure map, which contains roughly 900 primary $\alpha$ grains, the average grain diameter is found to be approximately $6 \mu \mathrm{m}$.

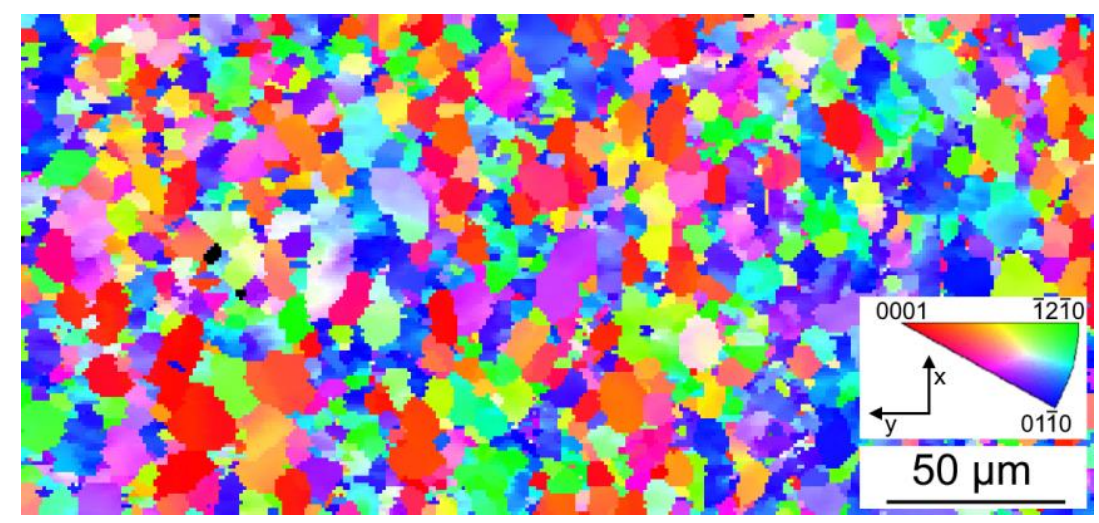

Figure 3. Inverse pole figure map (reference direction y) obtained by EBSD on the Ti-6Al-4V plate cross-section

The residual stress profile in the $x$ direction as a function of the distance $y$ from the laser shock peened surface is shown in Figure 4. This graph includes data from synchrotron XRD, [11] 
showing the values computed using individual diffraction peaks $(0002),(11 \overline{2} 0),(10 \overline{10})$ and (10i2), and data obtained by eigenstrain modelling. [20] It can be observed that the FIB-DIC ring-core measurements, with core diameter $\emptyset=10 \mu \mathrm{m}$, are in very good agreement with the synchrotron XRD data and eigenstrain model. It is found that a compressive residual stress of approximately $350 \mathrm{MPa}$ is present in the near-surface region. This changes to a tensile residual stress at a depth of $y \approx 1.5 \mathrm{~mm}$, which reaches a maximum value of approximately $100 \mathrm{MPa}$ at a depth of $y \approx 2 \mathrm{~mm}$. At a depth of $y \approx 6 \mathrm{~mm}$ the residual stress becomes compressive again. It can also be observed that the residual stress profile is roughly linear at depths beyond $y \approx 2 \mathrm{~mm}$, which is a result of the elastic bending response due to the plastic deformation in the nearsurface layers. This shows that the laser shock peening treatment only induced significant plastic deformation up to a depth of approximately $2 \mathrm{~mm}$. [20]

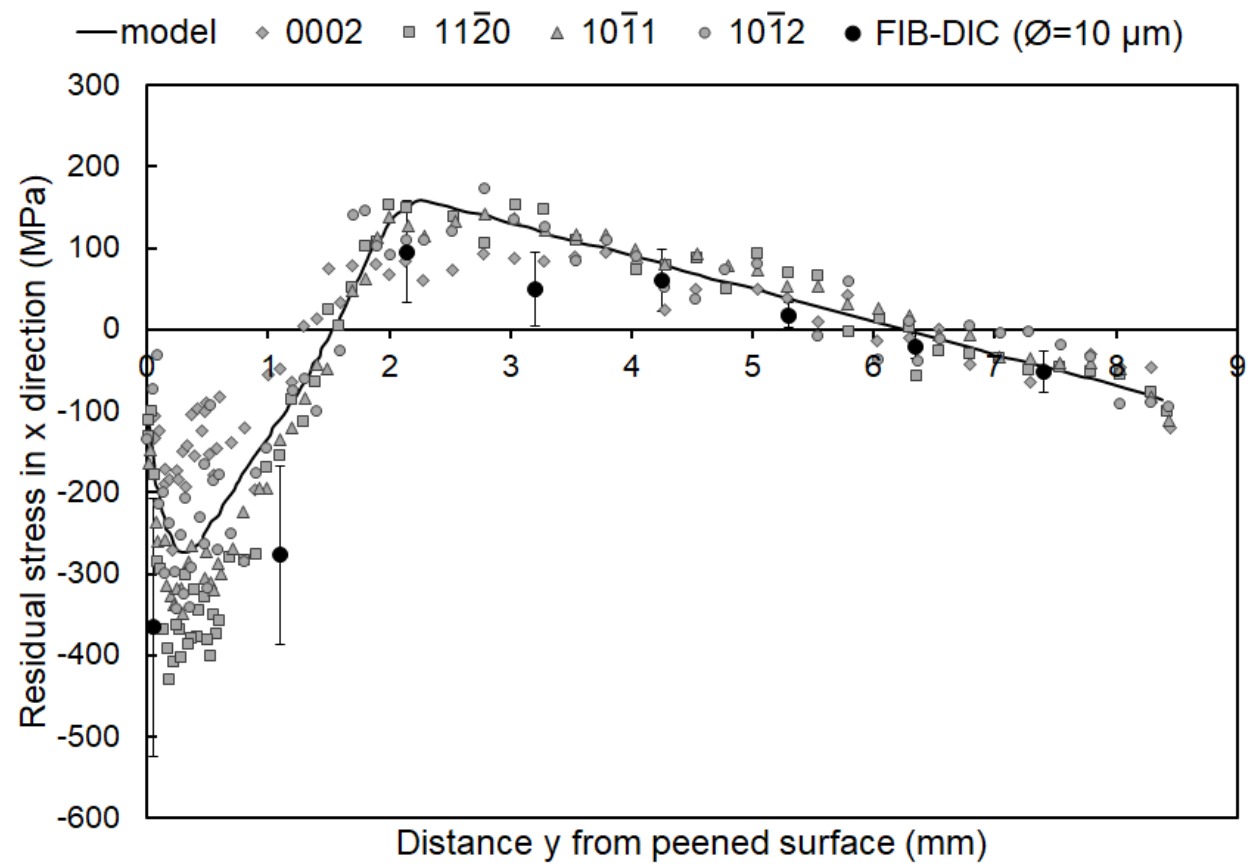

Figure 4. Residual stress in $x$ direction versus distance from laser shock peened surface, as determined by FIB-DIC ring-core milling with core diameter $\varnothing=10 \mu$, by synchrotron XRD using

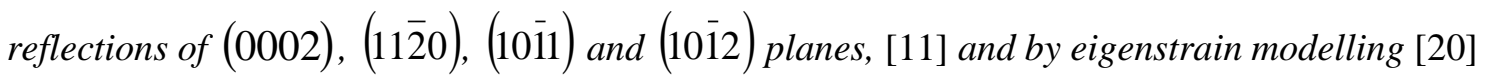


Figure 5 shows the residual stress values in the $x$ direction as a function of the distance $y$ from the laser shock peened surface for all FIB-DIC ring-core measurements. This includes the measurements with core diameter $\varnothing=10 \mu \mathrm{m}$ and those with $\emptyset=5 \mu \mathrm{m}$. It can be observed that the data with $\emptyset=5 \mu \mathrm{m}$ shows a high degree of scatter with respect to the data with $\emptyset=10 \mu \mathrm{m}$. The most remarkable deviation occurs for the data points that are closest to the peened surface. The point with $\emptyset=10 \mu \mathrm{m}$ shows that there is residual compressive stress at this location, which is in agreement with the XRD data and eigenstrain model (see Figure 4). However, the two data points with $\emptyset=5 \mu \mathrm{m}$ show that there is residual tensile stress of fluctuating magnitude.

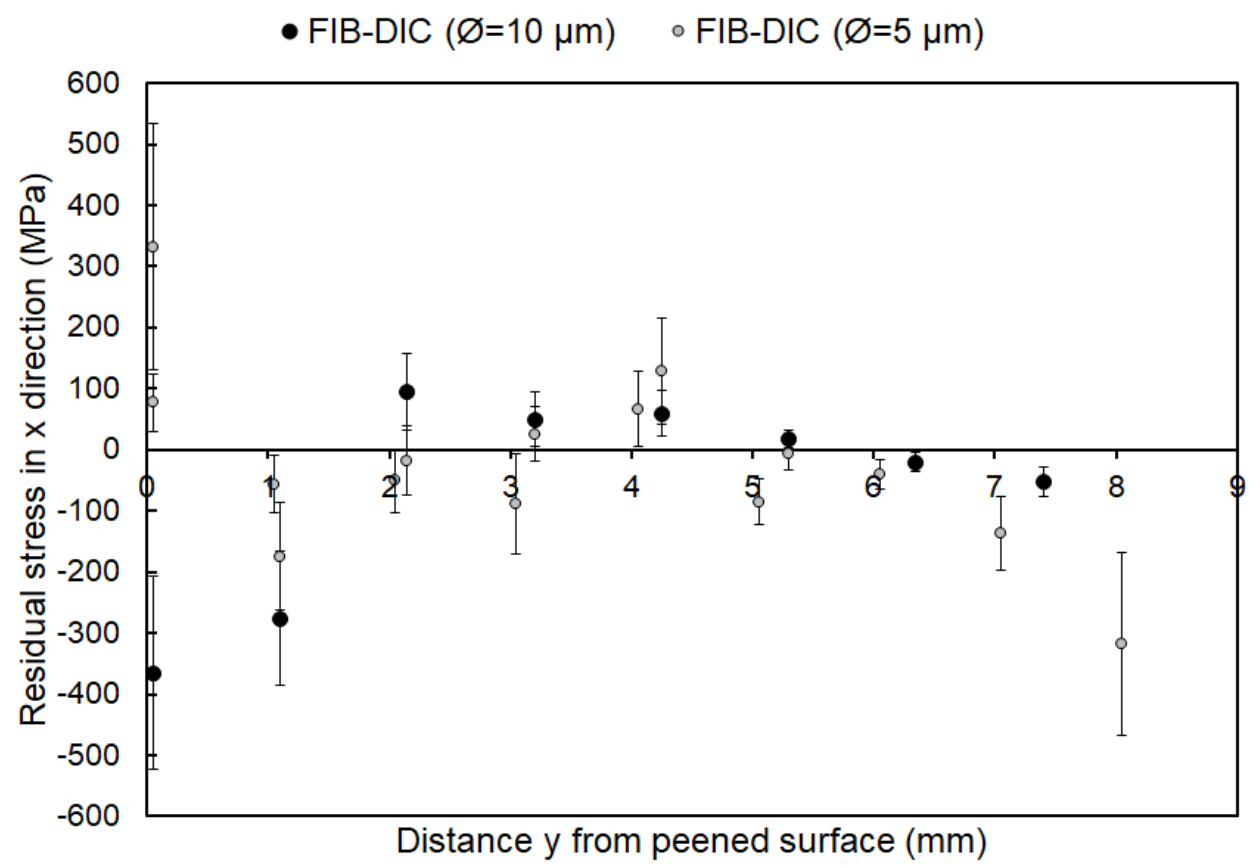

Figure 5. Residual stress in $x$ direction versus distance from laser shock peened surface, as determined by FIB-DIC ring-core milling with core diameter $\emptyset=10 \mu \mathrm{m}$ or $\emptyset=5 \mu \mathrm{m}$

\section{Discussion}

In order to provide an explanation for the results obtained by FIB-DIC ring-core milling, it is necessary to consider the different contributions that compose the total residual stress. As already mentioned in the introduction, residual stress can be classified according to different 
length scales into Type I, II and III residual stresses. [13] A key factor of this classification is the additive nature of the three contributions: [24]

$$
\sigma^{t o t}=\sigma^{I}+\sigma^{I I}+\sigma^{I I I}
$$

In other words, the total residual stress $\sigma^{\text {tot }}$ is equal to the sum of Type I $\left(\sigma^{I}\right)$, Type II $\left(\sigma^{I I}\right)$ and Type III $\left(\sigma^{I I I}\right)$ residual stress. Type I residual stress refers to macroscopic or long-range stress as a result of inelastic deformation such as bending, rolling, or, in this case, laser shock peening. Type II residual stress is a result of intergranular interactions caused by neighbouring grain morphologies and orientations, the presence of different phases or precipitates etc. These interactions lead to differences between the grain average residual stress and the macroscopic residual stress. Finally, Type III residual stress represents the variation within individual grains and can be attributed to e.g. dislocations, twinning etc. [19]

These three types of residual stress are illustrated in Figure 6, which shows the stress variation along a line profile through a polycrystal. Additionally, this figure represents FIB-DIC ringcore geometries with two different core diameters: one of the same order of magnitude as the grain size, and one roughly twice the average grain size. In the first case, the gauge volume, i.e. the micropillar volume, is small enough to contain only one or two grains. As a result, the measured residual stress in this case will be very sensitive to variations of Type II. In the second case, however, the gauge volume contains several grains, which means that the Type II contributions of those grains will be averaged out. Therefore, the measured residual stress in this case will be much closer to the macroscopic (Type I) value. It should be noted that the illustration in Figure 6 is two-dimensional and that the micropillar can also contain subsurface grains. However, it has been shown recently that the residual stress measured by ring-core FIBDIC is dominated by the contribution of the top layers up to a depth of approximately one third 
of the core diameter. [25] This essentially means that the effective gauge volume is roughly three times smaller than the micropillar volume.

This logical line of reasoning provides a plausible explanation for the results obtained in this study, which show that for an average grain diameter of $6 \mu \mathrm{m}$ FIB-DIC ring-core measurements with core diameter $\emptyset=5 \mu \mathrm{m}$ result in highly scattered residual stress values, whereas measurements with $\emptyset=10 \mu \mathrm{m}$ result in residual stress values that are closer to the macroscopic residual stress as determined by synchrotron XRD. It would also be reasonable to assume that a further increase in core diameter would result in residual stress values that are even closer to the macroscopic residual stress, because the number of considered grains would increase and the Type II contributions would be averaged out even further. These results show that the FIBDIC ring-core technique can be tailored to determine either macro- or microscopic residual stress, by tuning the core diameter with respect to the grain size. 


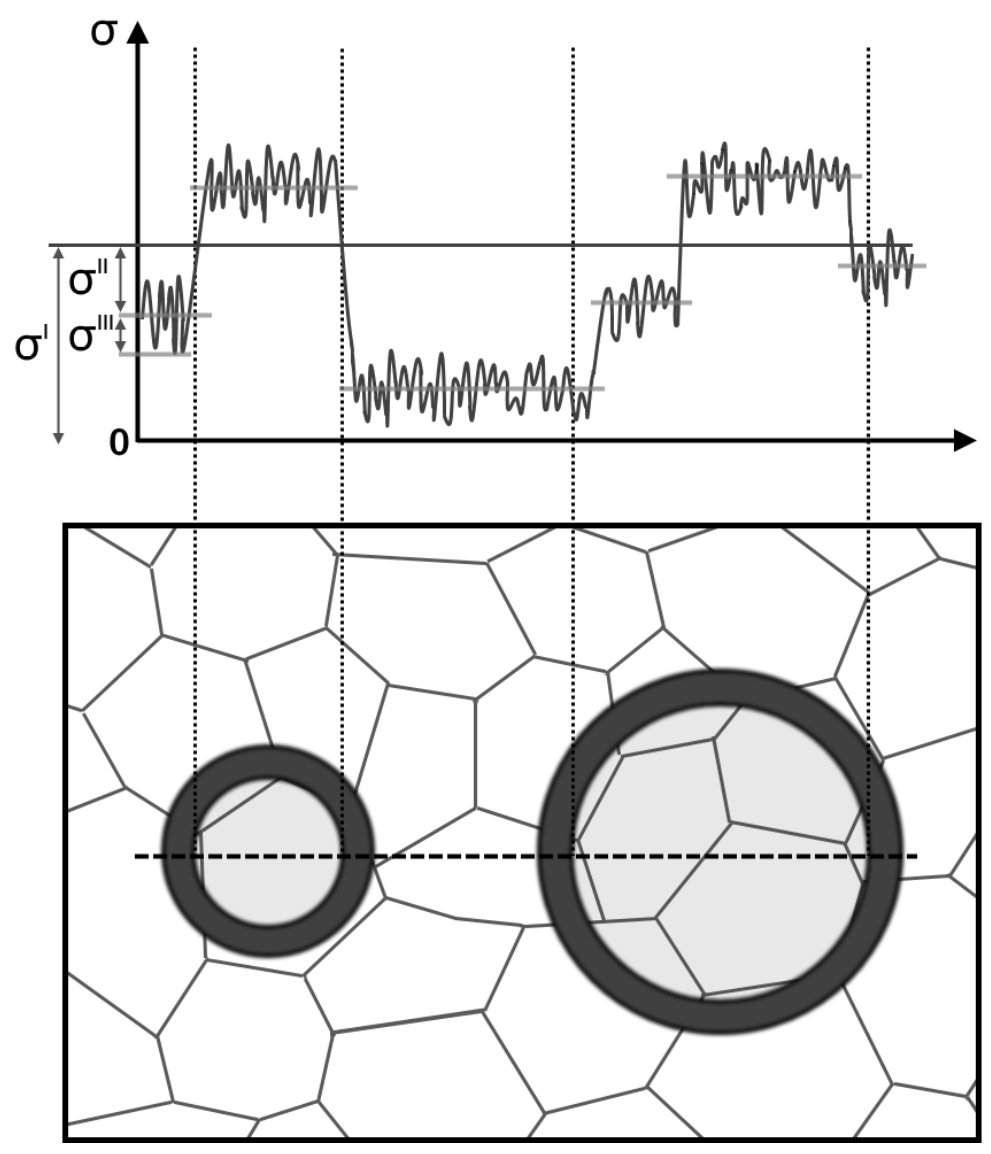

Figure 6. Illustration of Type I, Type II and Type III residual stress variation along a line profile through a polycrystal, and relation to the gauge volume of FIB-DIC ring-core geometries with two different core diameters

Bearing this in mind, the implications of the residual stress measurements in this study can now be contemplated. The results in Figure 5 show that the microscopic residual stress (FIB-DIC ring-core diameter $\emptyset=5 \mu \mathrm{m})$ can be significantly different from the macroscopic level $(\varnothing=10$ $\mu \mathrm{m})$. Most surprisingly it is observed that there can be local tensile residual stress even when the global residual stress is compressive, and vice versa. As argued above, this behaviour can be attributed to Type II residual stress, which is a result of neighbouring grain interactions. The hexagonal close-packed structure of the $\alpha$ phase of titanium is known to be highly anisotropic, both elastically and plastically. For example, Young's modulus of a single $\alpha$ Ti crystal is approximately $145 \mathrm{GPa}$ if loaded along the c axis, but only $100 \mathrm{GPa}$ if loaded parallel to the $\mathrm{c}$ 
axis. Plastic deformation is also more difficult if the load is applied along the $\mathrm{c}$ axis, because only pyramidal slip, which has a high critical resolved shear stress, can be activated. [16] Therefore, the crystallographic orientation of a grain and of its neighbouring grains has a significant influence on the local mechanical response to an applied load. For example, it has recently been shown that during a uniaxial tensile test the stress along the loading axis can decrease in some grains even when the applied load is increasing. [15] Another example of this effect is the phenomenon of load shedding during dwell fatigue, which describes a load redistribution from weak grains, with their c-axis perpendicular to the loading axis, to neighbouring strong grains, with their c-axis parallel to the loading axis. [26,27]

The observations in this study are an interesting contribution to the knowledge of neighbouring grain effects in titanium alloys, as they show that the microscopic residual stress distribution is also strongly affected by the local microstructure and crystallographic texture. This is an important complication when considering the local mechanical behaviour in response to an applied load. From an engineering perspective, a significant outcome is that even though laser shock peening induces residual compressive stress at the macro-scale, there can be local residual tensile stress at the micro-scale. This could have implications for fatigue crack initiation and short crack growth, which would warrant further research.

\section{Conclusions}

The residual stress in a laser shock peened titanium alloy plate has been analysed by the FIBDIC ring-core method using core diameters of 5 or $10 \mu \mathrm{m}$. As validation, these results were compared with a previously obtained set of measurements using high-energy synchrotron XRD and an eigenstrain model. The main conclusions can be summarised as follows: 
- The residual stress profile, as determined by ring-core FIB-DIC measurements with core diameter $10 \mu \mathrm{m}$, is in good agreement with the XRD data and eigenstrain model, showing residual compressive stress up to a depth of approximately $1.5 \mathrm{~mm}$.

- Ring-core FIB-DIC measurements with core diameter $5 \mu \mathrm{m}$ show strong deviations from this profile and in some cases even residual tensile stress values in the zone that was found to be under compression by the other experiments.

- These deviations are caused by Type II residual stress, which is present due to neighbouring grain interactions. The ring-core FIB-DIC measurements with core diameter $5 \mu \mathrm{m}$ are sensitive to these intergranular variations because the gauge volume is small with respect to the average grain diameter, which is approximately $6 \mu \mathrm{m}$. The FIB-DIC ring-core technique can therefore be tailored to determine either macro- or microscopic residual stress, by changing the core diameter with respect to the grain size.

- Laser shock peening of Ti-6Al-4V induces near-surface residual stress which is macroscopically compressive, but which can locally be tensile at the micro-scale. 


\section{References}

[1] R. Zhang, X. Zhou, H. Gao, S. Mankoci, Y. Liu, X. Sang, H. Qin, X. Hou, Z. Ren, G.L. Doll, A. Martini, Y. Dong, N. Sahai, C. Ye, The effects of laser shock peening on the mechanical properties and biomedical behavior of AZ31B magnesium alloy, Surf. Coatings Technol. 339 (2018) 48-56. doi:10.1016/j.surfcoat.2018.02.009.

[2] X.C. Zhang, Y.K. Zhang, J.Z. Lu, F.Z. Xuan, Z.D. Wang, S.T. Tu, Improvement of fatigue life of Ti-6Al-4V alloy by laser shock peening, Mater. Sci. Eng. A. 527 (2010) 3411-3415. doi:10.1016/j.msea.2010.01.076.

[3] A. King, A. Steuwer, C. Woodward, P.J. Withers, Effects of fatigue and fretting on residual stresses introduced by laser shock peening, Mater. Sci. Eng. A. 435-436 (2006) 12-18. doi:10.1016/J.MSEA.2006.07.020.

[4] A. Kanjer, L. Lavisse, V. Optasanu, P. Berger, C. Gorny, P. Peyre, F. Herbst, O. Heintz, N. Geoffroy, T. Montesin, M.C. Marco de Lucas, Effect of laser shock peening on the high temperature oxidation resistance of titanium, Surf. Coatings Technol. 326 (2017) 146-155. doi:10.1016/J.SURFCOAT.2017.07.042.

[5] C.S. Montross, T. Wei, L. Ye, G. Clark, Y.-W. Mai, Laser shock processing and its effects on microstructure and properties of metal alloys: a review, Int. J. Fatigue. 24 (2002) 1021-1036. doi:10.1016/S0142-1123(02)00022-1.

[6] J.J. Ruschau, R. John, S.R. Thompson, T. Nicholas, Fatigue crack nucleation and growth rate behavior of laser shock peened titanium, Int. J. Fatigue. 21 (1999) S199-S209. doi:10.1016/S0142-1123(99)00072-9.

[7] S.A. Martinez, S. Sathish, M.P. Blodgett, M.J. Shepard, Residual stress distribution on surface-treated Ti-6Al-4V by X-ray diffraction, Exp. Mech. 43 (2003) 141-147. doi:10.1007/BF02410495.

[8] A. Clauer, Laser shock peening for fatigue resistance, Surf. Perform. Titan. (1997).

[9] A. Umapathi, S. Swaroop, Residual stress distribution in a laser peened Ti-2.5Cu alloy, Surf. Coatings Technol. 307 (2016) 38-46. doi:10.1016/J.SURFCOAT.2016.08.053.

[10] R. Sonntag, J. Reinders, J. Gibmeier, J.P. Kretzer, Fatigue performance of medical 
Ti6Al4V alloy after mechanical surface treatments, PLoS One. 10 (2015) e0121963. doi:10.1371/journal.pone.0121963.

[11] A.M. Korsunsky, J. Liu, D. Laundy, M. Golshan, K. Kim, Residual elastic strain due to laser shock peening: Synchrotron diffraction measurement, J. Strain Anal. Eng. Des. 41 (2006) 113-120. doi:10.1243/03093247JSA139.

[12] S. Keller, S. Chupakhin, P. Staron, E. Maawad, N. Kashaev, B. Klusemann, Experimental and numerical investigation of residual stresses in laser shock peened AA2198, J. Mater. Process. Technol. $255 \quad$ (2018) 294-307. doi:10.1016/J.JMATPROTEC.2017.11.023.

[13] E. Macherauch, Residual Stresses, in: G.C. Sih, E. Sommer, W. Dahl (Eds.), Appl. Fract. Mech. to Mater. Struct., Springer Netherlands, Dordrecht, 1984: pp. 157-192.

[14] J. Everaerts, B. Verlinden, M. Wevers, Investigation of fatigue crack initiation facets in Ti-6Al-4V using focused ion beam milling and electron backscatter diffraction, J. Microsc. 267 (2017) 57-69. doi:10.1111/jmi.12547.

[15] H. Abdolvand, J. Wright, A.J. Wilkinson, Strong grain neighbour effects in polycrystals, Nat. Commun. 9 (2018) 171. doi:10.1038/s41467-017-02213-9.

[16] G. Lütjering, J.C. Williams, Titanium, Springer-Verlag Berlin Heidelberg, 2007.

[17] A.M. Korsunsky, M. Sebastiani, E. Bemporad, Focused ion beam ring drilling for residual stress evaluation, Mater. Lett. 63 (2009) 1961-1963. doi:10.1016/J.MATLET.2009.06.020.

[18] A.M. Korsunsky, M. Sebastiani, E. Bemporad, Residual stress evaluation at the micrometer scale: Analysis of thin coatings by FIB milling and digital image correlation, Surf. Coatings $\quad$ Technol. $205 \quad$ (2010) 2393-2403. doi:10.1016/J.SURFCOAT.2010.09.033.

[19] E. Salvati, A.M. Korsunsky, An analysis of macro- and micro-scale residual stresses of Type I, II and III using FIB-DIC micro-ring-core milling and crystal plasticity FE modelling, Int. J. Plast. 98 (2017) 123-138. doi:10.1016/J.IJPLAS.2017.07.004.

[20] A.M. Korsunsky, Residual elastic strain due to laser shock peening: Modelling by 
eigenstrain distribution, J. Strain Anal. Eng. Des. 41 (2006) 195-204. doi:10.1243/03093247JSA141.

[21] A.J.G. Lunt, A.M. Korsunsky, A review of micro-scale focused ion beam milling and digital image correlation analysis for residual stress evaluation and error estimation, Surf. Coatings Technol. 283 (2015) 373-388. doi:10.1016/J.SURFCOAT.2015.10.049.

[22] A.M. Korsunsky, A Critical Discussion of the $\sin 2 \psi$ Stress Measurement Technique, in: Mater. Sci. Forum, Trans Tech Publications, 2008: pp. 219-224. doi:10.4028/www.scientific.net/MSF.571-572.219.

[23] A.M. Korsunsky, On the modelling of residual stresses due to surface peening using eigenstrain distributions, J. Strain Anal. Eng. Des. 40 (2005) 817-824. doi:10.1243/030932405X30984.

[24] E. Macherauch, Introduction To Residual Stress, in: Residual Stress., Elsevier, 1987: pp. 1-36. doi:10.1016/B978-0-08-034062-3.50011-2.

[25] A.M. Korsunsky, E. Salvati, A.G.J. Lunt, T. Sui, M.Z. Mughal, R. Daniel, J. Keckes, E. Bemporad, M. Sebastiani, Nanoscale residual stress depth profiling by Focused Ion Beam milling and eigenstrain analysis, Mater. Des. 145 (2018) 55-64. doi:10.1016/j.matdes.2018.02.044.

[26] J. Everaerts, D. Gontcharov, B. Verlinden, M. Wevers, The influence of load holds on the fatigue behaviour of drawn Ti-6Al-4V wires, Int. J. Fatigue. 98 (2017) 203-211. doi:10.1016/J.IJFATIGUE.2017.01.043.

[27] M.. Bache, A review of dwell sensitive fatigue in titanium alloys: the role of microstructure, texture and operating conditions, Int. J. Fatigue. 25 (2003) 1079-1087. doi:10.1016/S0142-1123(03)00145-2. 